\title{
Las metáforas sobre el profesor y el aprendizaje de estudiantes de Maestría de Brasil y España
}

\section{The metaphors about the teacher and the students' learning from a Master's course in Brazil and Spain}

\author{
María Antonia Dávila ${ }^{1}$. Robson Novais ${ }^{2}$. Ana Belén Borrachero ${ }^{3}$. Lucía Mellado ${ }^{4}$
}

\begin{abstract}
Resumen: Este estudio analiza las metáforas personales sobre el profesor y el aprendizaje del alumnado, en una muestra de 23 profesores del Máster de Investigación sobre la Enseñanza y el Aprendizaje de las Ciencias Experimentales, Sociales y Matemáticas de la Universidad de Extremadura (España) y 19 profesores del Máster en Enseñanza, Historia y Filosofía de las Ciencias Experimentales y Matemáticas de la Universidad Federal de ABC (Brasil). El procedimiento de recogida de datos ha sido un cuestionario abierto realizado durante el curso académico 2014/15. Para el análisis, las metáforas se encuadraron en cuatro categorías: conductistas-transmisivas, cognitivas-constructivistas, situadas y autorreferenciadas. Los resultados indican que existe bastante coherencia entre las metáforas sobre el profesor y las del aprendizaje de los estudiantes. Tanto para el grupo de Brasil como para el de España el mayor número de metáforas pertenecen a la categoría cognitiva/ constructivista. La mayoría de las emociones asociadas a las metáforas son positivas.
\end{abstract}

Palabras clave: Metáfora. Aprendizaje. Máster. Profesorado. Brasil. España.

\begin{abstract}
This study analyze the personal metaphors on the teaching and the learning of students, of a sample of 23 teachers on the Master's degree in Research on the teaching and learning of experimental, social and mathematical sciences at University of Extremadura (Spain) and 19 teachers from the Master's degree in Education, History and Philosophy on the experimental and mathematical science course at the Federal University of ABC (Brazil). The data collection procedure was an open questionnaire carried out during the academic year 2014/2015. For the analysis, metaphors were framed in the four categories: behaviorist, constructivist-cognitive, situational and self-referential. The results show that there is enough consistency between the metaphors about the teacher and the learning student. Both for the group in Brazil and Spain the largest number of metaphors belong to the category cognitive/constructivist. Most of the emotions associated with the metaphors are positive.
\end{abstract}

Keywords: Metaphor. Learning. Master degree. Teacher. Brazil. Spain.

\footnotetext{
${ }^{1}$ Universidad de Extremadura, Facultad de Educación, Departamento de Didáctica de las Ciencias Experimentales y Matemáticas, Badajoz, España. E-mail: <mdavilaacedo@unex.es>.

${ }^{2}$ Ministério da Educação, Fundação CAPES, Brasília, DF.

${ }^{3}$ Universidad Internacional de La Rioja, Facultad de Educación, Logroño, España.

${ }^{4}$ Universidad Nacional de Educación a Distancia, Facultad de Ciencias Económicas y Empresariales, Madrid, España.
} 


\section{Introducción}

Desde la década de los 1980, la investigación sobre el profesorado ha evolucionado desde los estudios sobre las características personales y sobre los métodos de enseñanza hacia lo que piensan, saben y hacen los profesores en el aula. Como señalan Connelly, Clandinin y He (1997), una de las principales líneas de investigación para mejorar la educación y el aprendizaje de los alumnos es estudiar la expresión y construcción del conocimiento de los profesores. Sin embargo, el lenguaje que utiliza el profesor para hablar de sus concepciones, roles y de su actividad profesional no suele ser literal y estructurado, sino más bien simbólico y de carácter metafórico. Cada profesor elabora un pensamiento práctico profesional idiosincrásico, a partir de su experiencia personal y de la interacción social con el entorno que le rodea. A este pensamiento es difícil acceder y dotar de significados, ya que cada profesor tiene unas percepciones sobre la enseñanza y el aprendizaje, que les resultan difíciles de articular y de expresar de una forma estructurada.

Las metáforas personales del profesorado son un medio para articular el pensamiento y para establecer puentes entre las concepciones, el conocimiento práctico y la narrativa que describe la vida del aula (BUARAPHAN, 2011; KORTHAGEN, 2010). Como expresan Lakoff y Johnson (1986, p. 277): “Una gran parte de la autocomprensión consiste en la búsqueda de metáforas personales apropiadas que den sentido a nuestras vidas”. El estudio de las metáforas personales de los profesores se constituye así en un medio para averiguar los referentes implícitos que sustentan las concepciones, así como los modelos docentes en el aula, ya que como señalan numerosas investigaciones (BOUJAOUDE, 2000; GURNEY, 1995; TOBIN; TIPPINS; GALLARD, 1994) las metáforas personales de los profesores influyen poderosamente en su conducta docente en el aula.

Además, numerosos trabajos han mostrado que los profesores realizan cambios en sus concepciones y en su práctica en el aula cuando son capaces de elaborar nuevas metáforas compatibles con tales cambios (MARTÍNEZ; SAULEDA; HUBER, 2001; PINNEGAR et al., 2011; THOMAS; BEAUCHAMP, 2011; TOBIN; TIPPINS; GALLARD, 1994). Las metáforas pueden crear realidades sociales y convertirse en guía para las acciones futuras que se ajustarán a la metáfora. En palabras de Lakoff y Johnson (1986, p. 198): “[...] las metáforas pueden ser profecías que se cumplen".

Una metáfora es la sustitución o transposición de una idea o concepto por otro que tenga con él una cierta relación de semejanza objetiva o subjetiva para el emisor. Para Lakoff y Johnson (1986), lo esencial de la metáfora es comprender y experimentar una cosa en términos de otra. Las metáforas sirven de imágenes para recrear el mundo real y se han utilizado como un recurso expresivo en la literatura, en la oratoria, en la música y en numerosas expresiones artísticas y de comunicación. La lingüística estudia las metáforas desde la semántica, que profundiza en el concepto de anomalía léxica, y desde la pragmática, que trata de explicar la influencia que tienen las metáforas en el comportamiento de los hablantes y el papel que desempeñan los mecanismos heurísticos en las estructuras mentales (VELASCO SACRISTÁN, 2002). Desde la psicolingüística se estudia la correlación entre comportamiento lingüístico y procesos psicológicos subyacentes por lo que la metáfora sería un mecanismo heurístico que se manifiesta lingüísticamente. Las metáforas lingüísticas serían sólo la punta del iceberg de procesos cognitivos más básicos (DE BUSTOS, 2000). 
Las metáforas tienen un significado más profundo que el de ser un mero recurso expresivo, ya que constituyen un mecanismo esencial de la mente, que estructura gran parte del sistema conceptual por medio de relaciones metafóricas, y son un principio fundamental del pensamiento y la acción (LAKOFF; JOHNSON, 1986). Las metáforas constituyen un medio para comprender el mundo y son como lentes, pantallas o filtros de lo que somos y de cómo nos vemos en determinada situación (SABAN, 2010). Para Duffé Montalván (2004), actúan como un código de valores compartidos por otros miembros de la comunidad cultural y lingüística.

Para Lakoff y Johnson (1986), la teoría cognitiva de la metáfora explica como el individuo es capaz de construir conceptos abstractos a partir de imágenes esquemáticas y de conceptos directamente ligados a la experiencia. De Bustos (2000), también destaca el sentido cognitivo de la metáfora, tanto en la perspectiva constructivista, porque construyen y reorganizan una realidad, como en la perspectiva realista, porque descubren nuevos elementos o relaciones previamente existentes con la realidad. Las metáforas están presentes en el contexto del descubrimiento científico (CONTENÇAS; LEVY, 1999), y en el contexto de su justificación y comunicación (KINOUCHI; KINOUCHI; MANDRA, 2012), ya que son un componente esencial del razonamiento, la argumentación y la inferencia científica, que son procesos fundamentalmente analógicos. Las metáforas son como semillas que germinan en nuevas ideas y conocimientos (TOBIN; TIPPINS, 1996).

Los profesores construyen sus metáforas a partir de sus antecedentes escolares y de su propia experiencia personal (BEN-PERETZ; MENDELSON; KRON, 2003), por lo que tienen un fuerte componente afectivo (TOBIN; TIPPINS, 1996). En la enseñanza hay aspectos emocionales, que influyen en las acciones y en la toma de decisiones de los profesores (OTERO, 2006). Los dominios cognitivos y afectivos están relacionados y el segundo ejerce una poderosa influencia sobre el primero (DAY; LEICH, 2001). Las emociones son muy importantes para todos los profesores, pero especialmente para los profesores en formación y principiantes (BELLOCCHI et al., 2014; DÁVILA et al., 2015; HARGREAVES, 2005; MELLADO, L. et al., 2014, MELLADO, V. et al., 2014; ZEMBYLAS, 2004). Las primeras experiencias de enseñanza están llenas de tomas de decisiones, son emocionalmente muy fuertes y pueden ser traumáticas para los futuros profesores, que en esta etapa son especialmente vulnerables, generándoles emociones negativas como ansiedad, inseguridad, irritación o decepción. Estas emociones negativas pueden fijar estrategias conductistas, dirigidas hacia el control y la supervivencia, que son muy resistentes al cambio en el futuro. Las metáforas sirven de puente para unir el mundo cognitivo y afectivo y pueden ayudar a los profesores a tomar conciencia de sus sentimientos y emociones (REBOLLO et al., 2013).

Existen distintas propuestas de modelos para clasificar las metáforas personales de del profesorado. Martínez, Sauleda y Huber (2001) categorizaron las metáforas en tres categorías: conductistas/empiristas; cognitivas/constructivistas; y situadas o sociohistóricas. Leavy, McSorley y Boté (2007) mantienen las categorías de Martínez, Sauleda y Huber (2001), pero encuentran que algunas metáforas son difíciles de clasificar en las categorías propuestas por lo que añaden una cuarta categoría: la autorreferencial. En nuestro estudio adaptamos las cuatro categorías de Leavy, McSorley y Boté (2007): la conductista-transmisiva (el alumno como un aprendiz pasivo y el profesor como un transmisor de información), que tiene además la característica de ser una clase centrada en el profesor y el contenido; la cognitiva-constructivista (el alumno como un agente activo en el proceso de construcción de su propio conocimiento y el profesor como 
un facilitador del proceso); la situada o de aprendizaje social (con similares características de la anterior, pero haciendo más hincapié en el aprendizaje social que en el individual), estando ambas centradas en el alumno y el aprendizaje; las autorrefenciadas, que tienen un componente egocéntrico, cuyo significado es necesario analizar en cada caso.

Los dibujos se han utilizado en la investigación educativa para acceder a las concepciones de los profesores, ya que son como espejos de su identidad profesional y reflejan imágenes mentales que son una parte esencial de los procesos cognitivos (LÖFSTRÖM et al., 2015; MARKIC; EILKS, 2015). Los dibujos tienen un gran potencial para expresar metáforas (WEBER; MITCHELL, 1996) y con este sentido, se han utilizado en trabajos anteriores para representar las metáforas de los profesores (BUARAPHAN, 2011; MELLADO, L. et al., 2014).

Desde la década de los 1990, contamos con importantes estudios sobre las metáforas de los profesores (BULLOUGH JR., 1991; CONNELLY; CLANDININ; HE, 1997; RITCHIE, 1994; TOBIN; TIPPINS; GALLARD, 1994). Sin embargo, coincidimos con Shaw, Barry y Mahlios (2008) en que las metáforas deben seguir siendo objeto de investigación en aspectos menos tratados. En trabajos anteriores se han analizado las metáforas personales sobre el profesor y el aprendizaje de distintas muestras de futuros profesores de infantil, primaria y secundaria (MELLADO; BERMEJO; MELLADO, 2012; MELLADO et al., 2013a, 2013b, 2016; MELLADO, L. et al., 2014). Sin embargo, nos parece importante ampliar la muestra a profesores que estén realizando el máster de investigación, ampliar la metodología incluyendo los propios dibujos, así como comparar los resultados entre profesores de Brasil y España, para determinar la influencia de los diferentes contextos formativos.

\section{Problema de investigación}

En este artículo analizamos las metáforas, y su componente emocional, de estudiantes de posgrado de Brasil y España de Máster Universitarios de Investigación Educativa. Los objetivos de este estudio son:

1. Averiguar las metáforas personales sobre su figura como profesores y sobre el aprendizaje del alumnado de una muestra de estudiantes de posgrado de Brasil y España de Máster Universitarios de Investigación Educativa.

2. Clasificar las metáforas de la muestra dentro de las categorías: conductista-transmisiva, cognitiva-constructivista, situadas y auto-referenciadas.

3. Analizar la representación gráfica de las metáforas a través de los dibujos.

4. Comparar los resultados de las muestras de Brasil y de España.

\section{Metodología}

La investigación se ha realizado durante el curso académico 2014-2015, con una muestra de licenciados universitarios en ciencias, economía, historia y graduados en Educación Primaria e Infantil, en la Facultad de Educación de la Universidad de Extremadura (España), y una muestra de licenciados en ciencias, historia, filosofía y portugués, en Pesquisa em formação de professores de ciências e matemáticas de la Universidad Federal de ABC (Brasil). 
La muestra de España la componen 23 profesores del Máster de Investigación sobre la Enseñanza y el Aprendizaje de las Ciencias Experimentales, Sociales y Matemáticas de la Universidad de Extremadura, de los cuales 14 son mujeres y 9 hombres. Respecto a la formación académica, el mayor número procede del Grado en Educación Primaria (40.90\%), seguidas de las Licenciaturas de Biología y Matemáticas (13.63\% cada una) e Ingenierías (9.09\%). El resto lo componen otras licenciaturas de ciencias (física y química), Licenciatura en Historia, Licenciatura en Economía y Grado en Educación Infantil.

La muestra de Brasil la componen 19 profesores del Máster en Enseñanza, Historia y Filosofía de las Ciencias Experimentales y Matemáticas de la Universidad Federal de ABC, de los cuales 10 son mujeres y 9 hombres. En relación a la formación académica, el mayor número procede de las Licenciaturas de Biología (26.31\%), Matemáticas (21.05\%), Química y Física (15.78\% cada una). El resto lo componen otras licenciaturas tales como Historia, Filosofía y Portugués, así como el Grado en Ciencias y Tecnología.

El procedimiento de recogida de datos ha sido un cuestionario anónimo en el que además del sexo y la edad y otros datos académicos se hacen cinco preguntas abiertas:

1. Cuando impartes clases en un aula, ¿con qué metáforas te identificarías como profesor o profesora?

2. Explica las razones que te llevan a identificarte con esas metáforas. Indica también las emociones que te provocan tus propias metáforas.

3. ¿Con qué metáforas identificarías a los alumnos en relación al aprendizaje?

4. ¿Explica las razones por las que identificas el aprendizaje con esas metáforas? Indica también las emociones que te provocan esas metáforas.

5. Haz un dibujo que represente tus metáforas como profesor/a y la relación con el proceso de aprendizaje de tus alumnos. Señala en el dibujo qué parte representa a los profesores, y cual a los estudiantes.

6. Antes de pasar el cuestionario se les informó sobre el significado y la importancia de las metáforas en educación, pero no se les dio ningún ejemplo de metáforas personales para no condicionar sus respuestas.

Como hemos señalado anteriormente, en nuestro estudio adaptamos las cuatro categorías de Leavy, Mcsorley e Boté (2007): la conductista-transmisiva, la cognitiva-constructivista, la situada o de aprendizaje social y la autorrefenciada. Estas categorías nos permiten utilizar las metáforas personales de los profesores para determinar las concepciones y los modelos implícitos de enseñanza asociados a las mismas.

Para encuadrar las metáforas en una categoría, se ha analizado el significado dado por el participante, pues una misma metáfora puede tener distintas interpretaciones y sustentarse en diferentes creencias. Como señalan Ritchie, Aubusson, e Harrison (2006), las metáforas son como espadas de doble filo que, según el significado del que las exprese, pueden tener interpretaciones opuestas y encuadrarse en categorías distintas.

Hemos incluido también algunos proverbios, sintagmas convencionales o modismos expresados por los profesores. Los modismos son frases cortas y fijas con sentido privativo, cuyo significado conjunto está asumido por el colectivo cultural y lingüístico, pero que no se deduce literalmente de las palabras que lo forman. Para Gibbs (1992 apud DUFFÉ MONTALVÁN, 2004) los modismos son como "metáforas cristalizadas" que encierran significados muy arraigados en una comunidad. 
En el cuestionario se les pide que realicen un dibujo que represente las metáforas como profesor y la relación con el proceso de aprendizaje de los alumnos. Para Markic y Eilks (2015) los dibujos son muy útiles para determinar si una clase está centrada en el profesor y el contenido o en los alumnos y el aprendizaje. Los dibujos permiten comparar las metáforas verbales con las representaciones gráficas y además, expresan aspectos como las emociones que son difíciles de articular con palabras.

Con respecto a las emociones que representan las metáforas, clasificamos las emociones en primarias/básicas o sociales (DAMASIO, 2010), y en positivas, negativas o neutras (BORRACHERO et al., 2014; BRÍGIDO et al., 2013). En otros trabajos se han considerado tanto las emociones expresadas explícitamente como las implícitas asociadas a determinadas metáforas (MELLADO et al., 2013a, 2013b, MELLADO, L. et al., 2014). En este caso solo consideramos las emociones explícitamente señaladas por los participantes.

Finalmente, se realizó un análisis descriptivo de frecuencias en cada grupo y categoría y se discutieron las razones por las que se identifican con las metáforas, contrastando los resultados con anteriores estudios.

\section{Discusión de los resultados}

\section{Metáforas sobre el profesor y sobre el aprendizaje}

Todos los participantes fueron capaces de expresar sus roles en términos de metáforas. El número total de metáforas expresadas del Grupo de España fue de 52 para el profesor y 39 para el aprendizaje. Para el profesor el $36.54 \%$ de las metáforas pertenecen a la categoría cognitiva/ constructivista, un $34.62 \%$ a la conductista/ transmisiva, un $15.38 \%$ a la situada y un $13.46 \%$ a la autorreferenciada. Para el aprendizaje del alumnado un $43.59 \%$ pertenecen a la categoría cognitiva/ constructivista, un $30.77 \%$ a la conductista/transmisiva, un $20.51 \%$ a la autorreferenciada, y un $5.13 \%$ a la situada.

El número total de metáforas expresadas del Grupo de Brasil fue de 23 para el profesor y 22 para el aprendizaje. Para el profesor el $54.55 \%$ de las metáforas pertenecen a la categoría cognitiva/ constructivista, un $40.91 \%$ a la conductista/ transmisiva, un $9.09 \%$ a la situada y un $0.00 \%$ a la autorreferenciada. Para el aprendizaje del alumnado un $39.13 \%$ pertenecen a la categoría cognitiva/ constructivista, un $21.74 \%$ a la conductista/transmisiva, un $30.43 \%$ a la autorreferenciada, y un $8.70 \%$ a la situada.

En el Gráfico 1, se representan los porcentajes de estas metáforas en las cuatro categorías de análisis para el profesor, comparando los grupos de Brasil y España.

Como puede observarse en el Gráfico 1, el mayor número de metáforas para el profesor se sitúa dentro de la categoría cognitiva/constructivista en ambos países, siendo mayor para el grupo de Brasil (54.55\%) que para el de España (36.54\%). Seguidamente, se encuentra la categoría conductista/transmisiva con un porcentaje mayor del grupo de Brasil (40.91\%) que el de España (34.62\%). Un porcentaje más pequeño lo componen las metáforas de las categorías situadas/aprendizaje social, siendo mayor en el grupo de España (15.38\%) que en el grupo de Brasil (9.09\%), y autorreferenciadas, 13.46 para el grupo de España y ninguna en el grupo de Brasil. 
Gráfico 1. Comparativa de los tipos de metáforas generales para el profesor en el grupo de España y en el grupo de Brasil

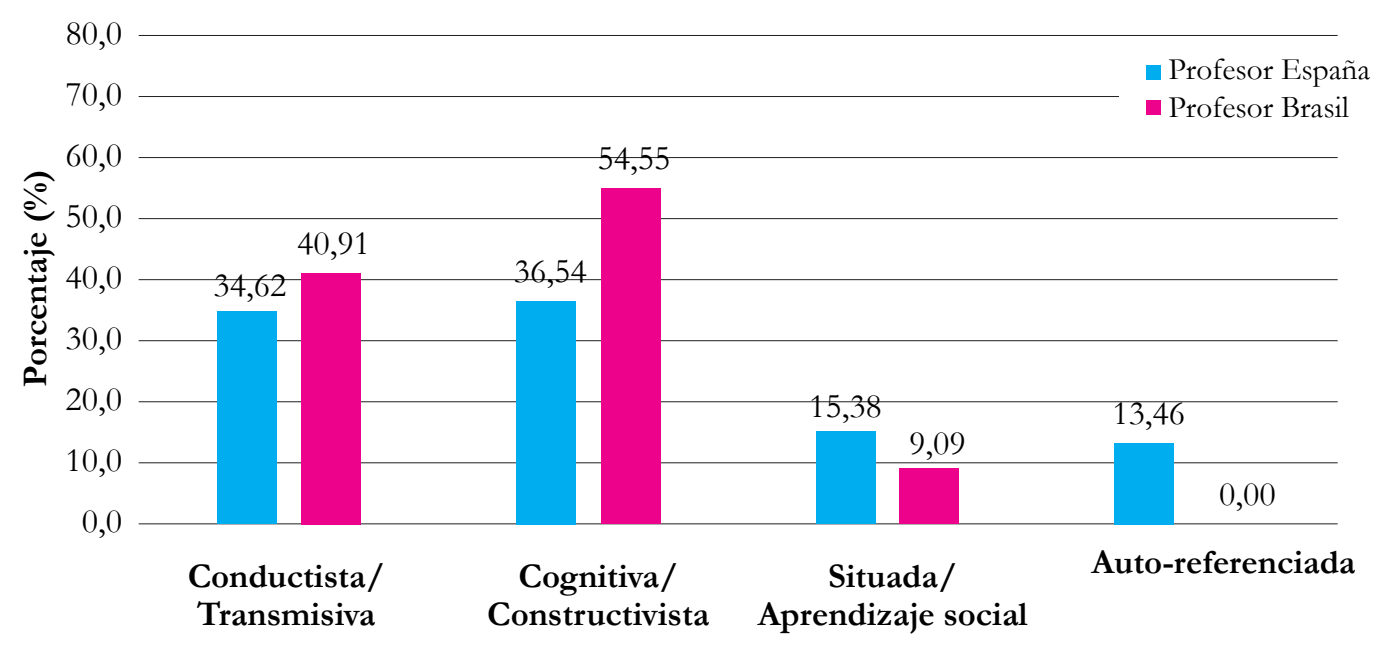

Fuente: Elaboración de los autores.

En el Gráfico 2, se representan los porcentajes de las metáforas en las cuatro categorías de análisis para el aprendizaje del alumnado, comparando los grupos de Brasil y España.

Gráfico 2. Comparativa de los tipos de metáforas generales para el aprendizaje en el grupo de España y en el grupo de Brasil

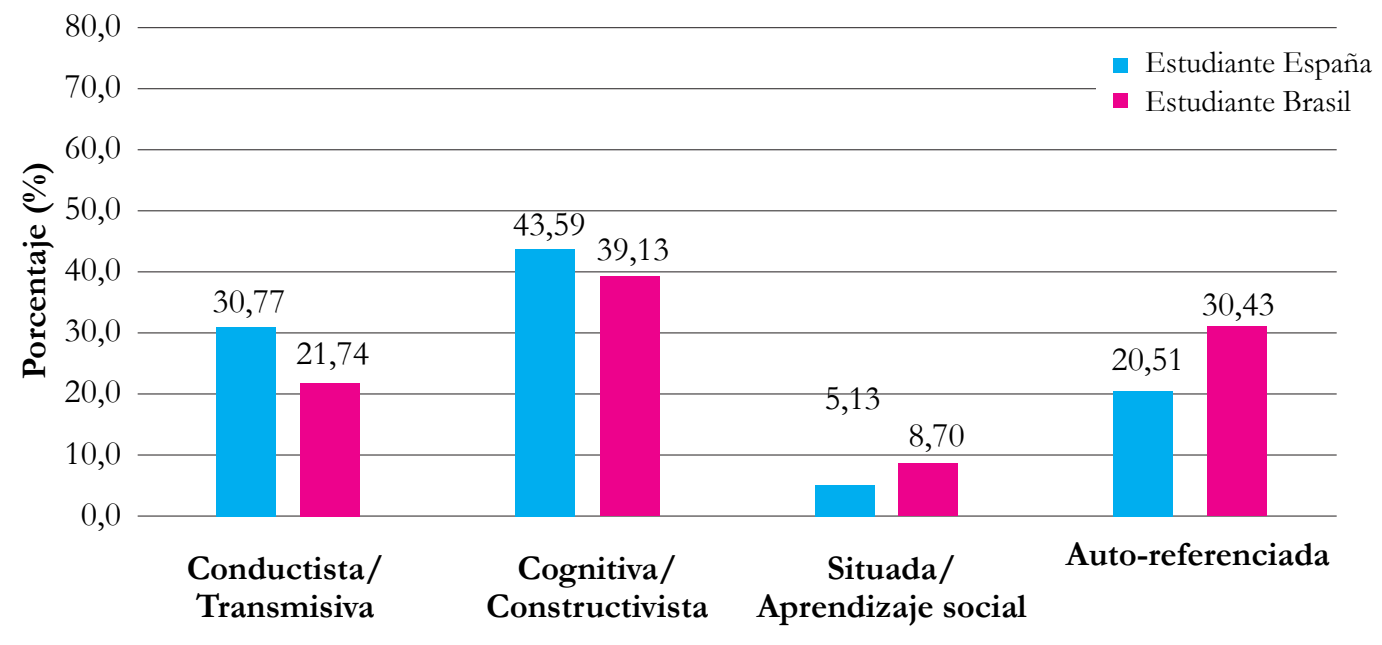

Fuente: Elaboración de los autores. 
Como puede observarse en el Gráfico 2, el mayor número de metáforas para el aprendizaje de los estudiantes se sitúa dentro de la categoría cognitiva/constructivista, siendo mayor para el grupo de España (43.59\%) que para el grupo de Brasil (39.13\%). Seguidamente, para el grupo de España se encuentra la categoría conductista/transmisiva (30.77\%), mientras el grupo de Brasil expresa un $21.74 \%$. Este porcentaje prácticamente se invierte en las autorreferenciadas, con un porcentaje del $30.43 \%$ en el grupo de Brasil y de un $20.51 \%$ en el grupo de España. El menor porcentaje en ambos grupos lo constituyen las metáforas de la categoría situadas/aprendizaje social, siendo mayor en el grupo de Brasil (8.70\%) que en el grupo de España (5.13\%).

a) Metáforas conductistas-transmisivas

En la categoría conductista/transmisiva, la metáfora dominante es la del profesor como trasmisor de conocimientos y la del alumno como receptor pasivo de estos conocimientos (LEVY; MCSORLEY; BOTÉ, 2007; MARTÍNEZ; SAULEDA; HUBER, 2001; SEUNG; PARK; NARAYAN, 2011). En el grupo de España encontramos metáforas centradas en la explicación del profesor como la del dibujo animado parlanchín, similar a la del loro parlanchín señalada por un profesor de ciencias de secundaria en formación (MELLADO; BERMEJO; MELLADO, 2012), metáfora que provoca la emoción básica negativa de la tristeza; la del pregonero que da muchas voces; la de correa de transmisión; la de transmisor de conocimiento; la del eslabón de una cadena; la de enrollarse como una persiana, la de claro como el agua, referenciada para profesores en formación de infantil, primaria y secundaria (MELLADO et al., 2013b); o la del gazpacho porque repite muchas veces, que provoca la emoción negativa social del cansancio. Con el mismo significado conductista/transmisivo está la metáfora de la actriz de teatro para el profesor y del público para los estudiantes (grupo de España), clasificada en esta categoría porque la actriz es la protagonista y el público es pasivo. En el grupo de Brasil metáforas encuadradas en esta categoría son las del historiador, la de la enciclopedia o la del hablador. Estas metáforas del profesor se relacionan con metáforas del alumno receptor pasivo del aprendizaje como la esponja, un cajón vacío (grupo de España) o un candado que sólo se abre cuando algo le interesa al alumno (grupo de Brasil) (MARTÍNEZ; SAULEDA; HUBER, 2001; SABAN, 2010).

En la Figura 1 se representan dos dibujos de cada grupo de las metáforas de esta categoría que representan la clase centrada en el profesor: el primero el profesor diccionario (España), también representado como la piedra Rosetta por el mismo participante, similar a la del profesor enciclopedia (Brasil), metáfora referenciada por Thomas y Beauchamp (2011), que se corresponde para los alumnos con cántaros vacíos que se van llenando con las explicaciones del profesor; el segundo el profesor hablador contador de historias (Brasil) y los alumnos como una audiencia escuchándolo pasivamente (MARKIC; EILKS, 2015).

La metáfora del recipiente vacío que es llenado por el profesor ha sido referenciada en otros trabajos (SABAN, 2010) como ejemplo del modelo conductista-transmisivo de una clase centrada en el profesor, depositario del conocimiento que transfiere a los alumnos. Estas metáforas son opuestas a las teorías constructivista que consideran que el alumno tiene ideas y concepciones y el aprendizaje debe partir de ellos para reconstruir los conocimientos. 
Figura 1. El profesor como un diccionario (España) y como contador de historias (Brasil)

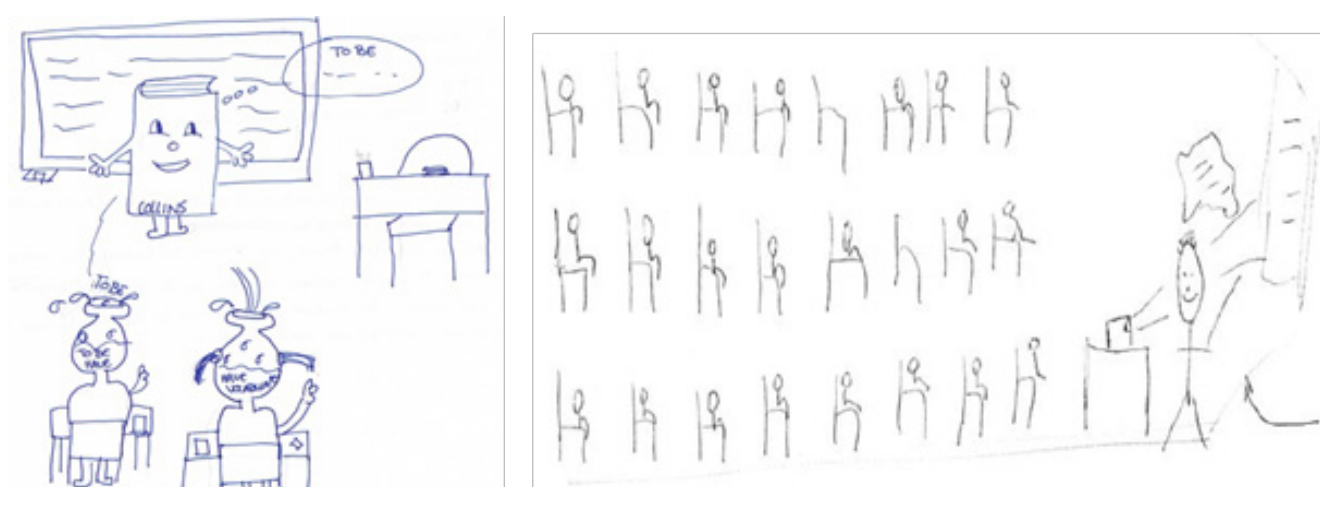

Fuente: Elaboración de los alumnos.

Otras metáforas para el profesor en esta categoría del grupo de España son la del horno en el que entran los alumnos-cubitos de hielo (Figura 2), aterrorizados por poder fundirse al entrar en contacto con el horno, metáfora que sin embargo, provoca en el participante emociones positivas como felicidad (básica) o sociales como confianza, valor y fuerza. La metáfora del albañil (KIM; DANFOTTH, 2012) que construye a su gusto las casas-alumnos, que tienen un papel pasivo de materia prima moldeada por el profesor (CRAWFORD, 2000). También, hemos identificado en esta categoría, por estar centrada en el profesor, la metáfora del corredor de fondo, porque habrá días u horas en que habrá dificultades que habrá que superar. En el grupo de España hay varias metáforas conductistas/transmisivas del profesor que expresan un liderazgo autoritario, como las del policía y controlador, porque les gusta el orden, controlar todo lo que sucede en la clase y que los alumnos sigan las normas al pie de la letra; la del domador del circo en la que los alumnos son las fieras que hay que domar.

En el grupo de Brasil las metáforas encuadradas en esta categoría son la del fantasma por ser invisible, la del poste al no ser ni oído ni percibido por los alumnos, la del hada porque piensan que soy de otro mundo, la del mal necesario como una inyección molesta que no soluciona el dolor, o la del guerrero de una batalla (Figura 2). La metáfora del guerrero expresa emociones defensivas negativas hacia los estudiantes. En la literatura se han identificado numerosas metáforas para el profesor asociadas a roles militares o de policías (SEFEROGLU; KORKMAZGIL; ÖLÇÜ, 2009; THOMAS; BEAUCAMP, 2011).

Figura 2. El profesor como un horno (España) y como un guerrero (Brasil) 

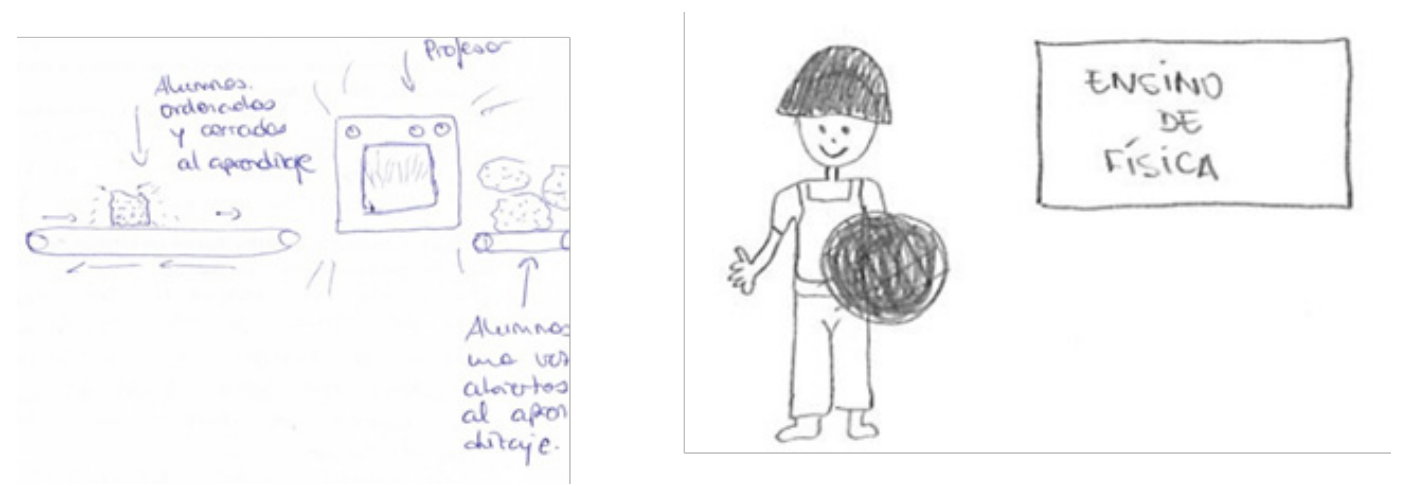

Fuente: Elaboración de los alumnos.

Dos participantes del grupo de España, identifican a los alumnos como esponjas (MARTÍNEZ; SAULEDA; HUBER, 2001; SABAN, 2010). La esponja la hemos clasificado como conductiva-transmisiva, cuando tiene el significado de absorber de forma pasiva lo que se le suministra, o como cognitiva-constructivista cuando se destaca la actitud de querer aprender todo, destacando el proceso de aprender más que el producto. Otras metáforas de esta categoría para los alumnos son los vasos rebosantes; un libro que hay que escribir; melones a los que les cuesta mucho aprender; los antieconomistas porque no quieren economizar su tiempo, no trabajan ni están atentos en el aula y no invierten el tiempo de clase al máximo; estancados, porque necesitan un empujón y motivación para realizar cualquier tarea.

El grupo de Brasil identifica a los alumnos en esta categoría con metáforas de animales como papagayos al repetir las cosas sin comprender lo que se dice; mariposas revoloteando de un lado para otro, sin centrarse en las tareas; o zombis que siguen las clases del profesor pero sin saber lo que se está haciendo. Una metáfora con emociones asociadas negativas es la del monstruo de siete cabezas.

b) Metáforas cognitivas-constructivistas

En esta categoría se encuentra el mayor número de metáforas expresadas por los grupos de Brasil y España, tanto para el profesor como para el aprendizaje. En estas metáforas el profesor se considera un educador y facilitador, y el alumno un aprendiz activo que construye poco a poco un aprendizaje significativo (BOUJAOUDE, 2000).

Metáforas en esta categoría para el profesor del grupo de España son la del entrenador (KIM; DANFOTTH, 2012), en la que la clase es un gimnasio de neuronas, a la que asocia la emoción positiva básica de la alegría y la emoción positiva social del entusiasmo; la del médico que ayuda, analiza cada caso de los pacientes-alumnos y solventa los problemas, tanto conceptuales como profesionales (MELLADO et al., 2013b); la del santo Job, por la emoción positiva social de la paciencia; la del punto de apoyo; la del intermediario; o la de la chispa que enciende la mecha, para motivar a los alumnos y hacer que sean autosuficientes. Uno de las participantes 
se considera un libro que van escribiendo tanto el profesor como los alumnos y en el que todos aprenden de todos, metáfora con un significado cognitivo-constructivista, que el participante asocia con emociones muy contradictorias: alegría (positiva básica), curiosidad (positiva social), sorpresa (neutra básica), temor (negativa básica) y frustración (negativa social). La metáfora anterior es diferente a la conductista-transmisiva del libro abierto, con el significado de centrar el modelo de enseñanza en la explicación del profesor, señalada por varios autores (ALARCÓN et al., 2014; SILLMAN; DANA, 2001; THOMAS; BEAUCHAMP, 2011). Otro participante se considera la pista del acertijo, no da la respuesta pero pone los medios para que el alumno alcance por sí mismo la respuesta.

Una de las participantes españolas se identifica con una actriz, con un significado cognitivo, como puede verse en el dibujo de la Figura 3, ya que los alumnos comparten activamente con ella la representación. En este mismo sentido, se encuentra la metáfora del grupo de Brasil del profesor artista y los alumnos artistas colaboradores de todo el proceso. Estos dibujos expresan perfectamente una clase centrada en los estudiantes y son similares a los identificados por Markic y Eilks (2015) para representar una clase de esta categoría.

Figura 3. El profesor como artista que comparte (España y Brasil)

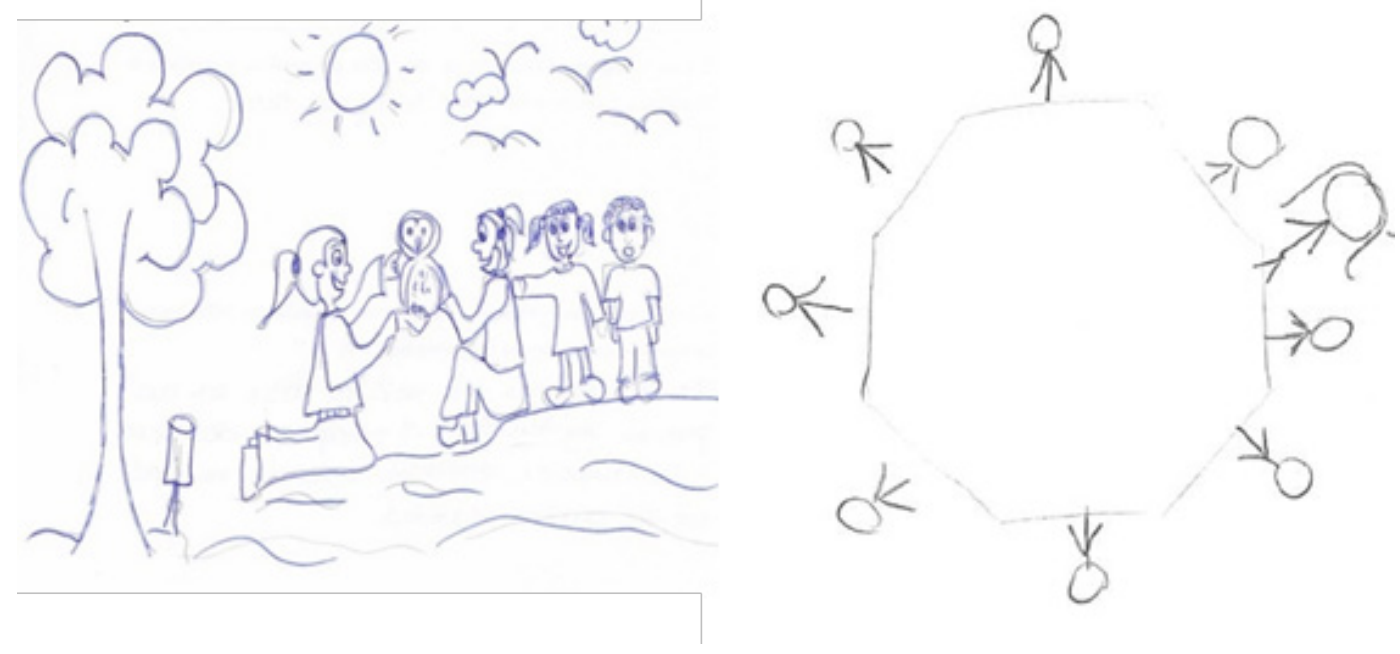

Fuente: Elaboración de los alumnos.

Tanto en el grupo de Brasil como en el de España hay profesores que se representan como un jardinero o un sembrador (Figura 4), con un significado cognitivo, que siembra, abona, riega y ayuda al crecimiento de las plantas o de las flores, metáforas analizada en numerosos estudios (ALARCÓN et al., 2014; BUARAPHAN, 2011; PATCHEN; CRAWFORD, 2011; SABAN, 2010). Complementariamente para los alumnos y el aprendizaje se indican en ambos grupos las metáforas del árbol, las plantas o las flores y sus fases de crecimiento, como orquídeas en tierra nueva, o rosas a punto de florecer; metáforas relacionadas con los estudiantes en 
estudio previos (BUARAPHAN, 2011; GURNEY, 1995; SABAN, 2010; SILLMAN; DANA, 2001). Estas metáforas están asociadas a emociones positivas tanto primarias (alegría/felicidad) como sociales (entusiasmo, motivación, etc.).

Figura 4. El profesor como jardinero (España) y como sembrador (Brasil)

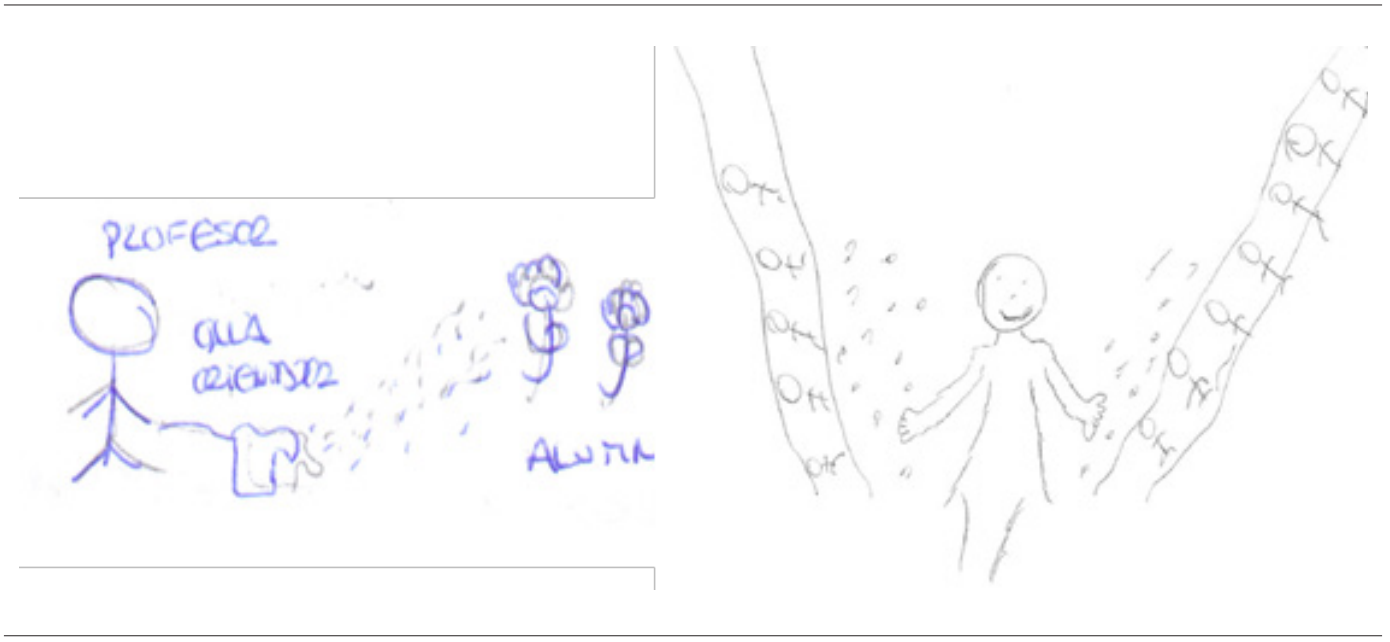

Fuente: Elaboración de los alumnos.

En esta categoría una de las participantes de la muestra de España se identifica con una flor de la que los alumnos-colibríes extraen el néctar (Figura 5). Otro participante del grupo de España representa al profesor con un camaleón, metáfora que indica flexibilidad y adaptación a los alumnos y a la propia clase (BOUJAOUDE, 2000; BUARAPHAN, 2011; BULLOUGH JR., 1991; MELLADO et al., 2013b; TOBIN; TIPPINS; GALLARD, 1994). En el grupo de Brasil, también se consideran cognitivas las metáforas para el profesor del ser-humano y del educador intelectual (Figura 5) que dibuja al profesor y al alumno del mismo tamaño y que se complementan.

Otras metáforas que indican adaptación son la del innovador del grupo de España, referenciada por Guerrero y Villamil (2002), o la del vehículo todoterreno, que tiene que adaptarse a diferentes caminos, a la que asocia la emoción positiva social de la confianza. La metáfora de Brasil del ilusionista, también indica flexibilidad y adaptación ya que tiene que cambiar continuamente su metodología. La metáfora del ilusionista, expresada por un profesor de biología es una metáfora mágica, también identificada por Grant (1992) en un profesor de física de secundaria que presenta su asignatura como algo mágico y maravilloso. Una metáfora asociada al cambio para los alumnos del grupo de Brasil son las orugas que se convierten en mariposas, metáfora encontrada en un estudio previo con profesores de secundaria españoles de economía (MELLADO et al., 2016). En ambos grupos encontramos metáforas cognitivas familiares para el profesor: la abuela, que cuida y aconseja, la madre protectora o el hermano mayor (TOBIN; TIPPINS; GALLARD, 1994). 
Figura 5. El profesor una como una flor de la que los alumnos-colibríes extraen el néctar (Grupo de España) y como educador intelectual (Grupo de Brasil)

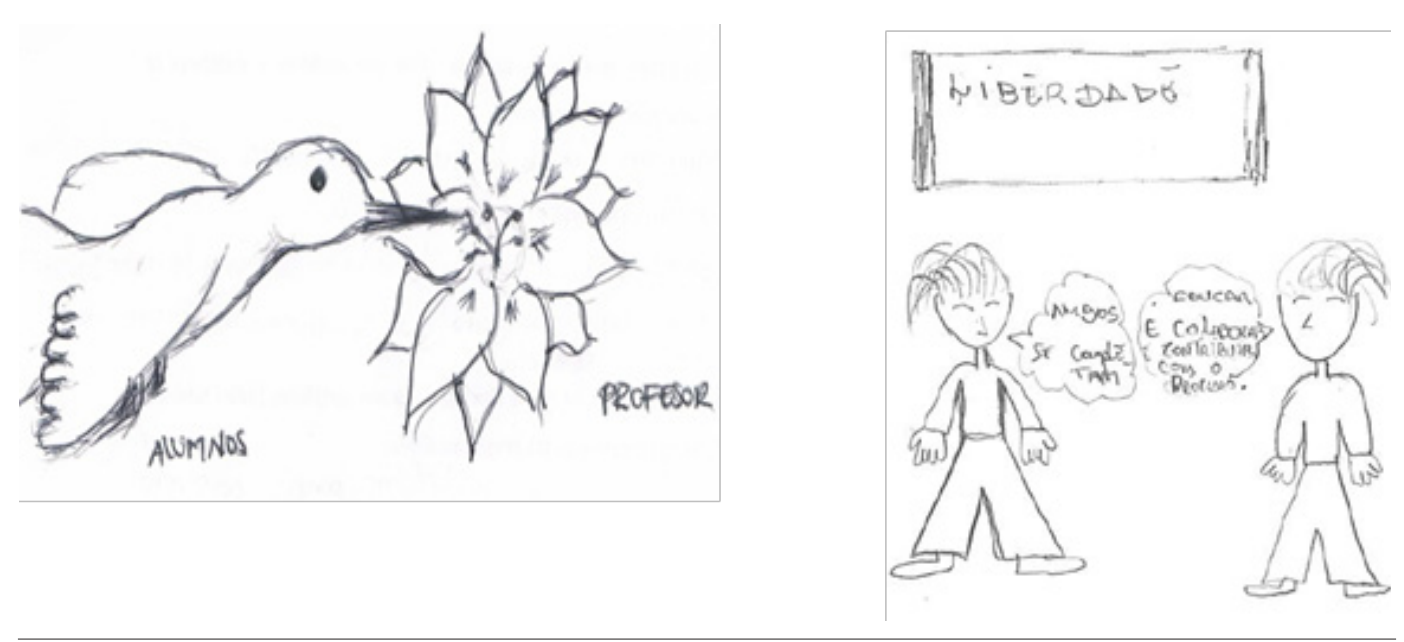

Fuente: Elaboración de los alumnos.

En el grupo de España no encontramos metáforas relacionadas con los contenidos concretos de las carreras previas de los participantes, un resultado coincidente con anteriores estudios (MAHLIOS; MASSENGILL-SHAW; BARRY, 2010; MELLADO; BERMEJO; MELLADO, 2012), en que las metáforas no están asociadas a contenidos concretos, sino que son expresión de una visión general de la enseñanza y del rol del profesor, formada de sus propias experiencias como alumnos y de sus experiencias de enseñanza.

Sin embargo, en el grupo de Brasil hay varias metáforas relacionadas con la formación previa de los participantes (Figura 6): un profesor de biología se representa como el árbol de la vida que necesita de la glucosa como combustible y del ADN como código para el desarrollo de la vida. Un profesor de química se representa como el equilibrio químico, flecha de doble vía o una mezcla de gases que interactúan entre sí, ya que considera el aula como un sistema dinámico donde los alumnos mejoran su formación e integración constantemente.

En esta categoría, participantes del grupo de España identifican a los alumnos con la metáfora de la esponja, con significado cognitivo que lo absorbe todo y que está abierta a todas las enseñanzas y a todo lo que ve en el viaje, el constructor de sueños, el barro que se moldea a sí mismo o atletas de un equipo (OLTHOUSE, 2014) que va a jugar una final, con una cantidad inmensa de potencial y talento que el profesor tiene que descubrir y potenciar. Una metáfora cognitiva, señalada para los alumnos por ambos grupos de Brasil y España es la caja de sorpresas, metáfora referenciada en estudios previos (MELLADO et al., 2013b), que lleva asociada la emoción básica de la sorpresa, una emoción fundamental para el aprendizaje científico (IZQUIERDO AYMERICH, 2013; KING et al., 2015). Otro del grupo de Brasil asocia el aprendizaje con una pared en construcción en la que todos tienen que aportar. 
Figura 6. Metáforas del profesor del grupo de Brasil, relacionadas con los contenidos: el árbol de la vida con el ADN como ramas, y el equilibrio químico entre gases

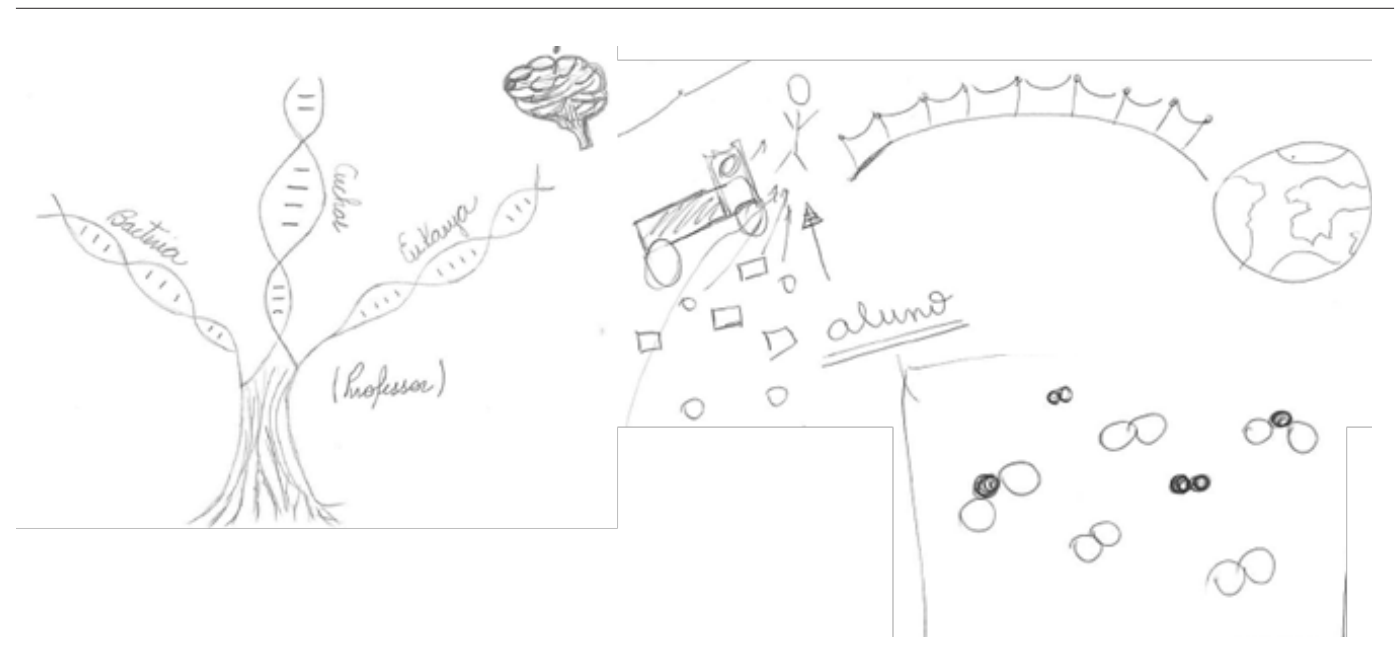

Fuente: Elaboración de los alumnos.

c) Metáforas situadas/aprendizaje social

En esta categoría se han expresado menos metáforas que en las categorías anteriores. En algunos casos puede ser debido a que son más difíciles de expresar y por otro a que los profesores asumen un rol más individualizado, en detrimento de las metáforas que hacen referencia a una enseñanza social y colaborativa. Los participantes del grupo de España han expresado las metáfora del orientador y guía, que comprenden, motivan y ayudan, pero tienen además un significado más social y cooperativo (ALARCÓN et al., 2014; GURNEY, 1995; LEAVY; MCSORLEY; BOTÉ, 2007; RITCHIE, 1994), y que los participantes asocian a la emoción positiva básica de la felicidad; o la del camino (Figura 7) que tienen que recorrer los alumnos-pájaros ayudados por el profesor (MCGRATH, 2006; THOMAS; BEAUCHAMP, 2011), que asocian a las emociones positivas sociales de la satisfacción y el orgullo; o la del conductor (SEFEROGLU; KORKMAZGIL; ÖLÇÜ, 2009); o la del paso de cebra, que da seguridad para cruzar a los alumnos-peatones.

Tanto en el grupo de Brasil como en el de España señalan para el profesor la metáfora de la lámpara, la vela o la luz que guía el camino (Figura 7), identificada como situada en numerosos trabajos (GURNEY, 1995; HAMILTON, 2016; MCGRATH, 2006; MELLADO et al., 2013b; RITCHIE, 1999; SILLMAN; DANA, 2001; THOMAS; BEAUCHAMP, 2011).

Para los alumnos, uno de los participantes del grupo de España indica la de perdidos, que necesitan buenos profesores que sepan mostrarles el camino y otro de Brasil los identifica con corrientes de aire que llevan al conocimiento (Figura 7). 
Figura 7. Metáforas del profesor como un camino (grupo de España) y como la luz que alumbra el camino (Grupo de Brasil)
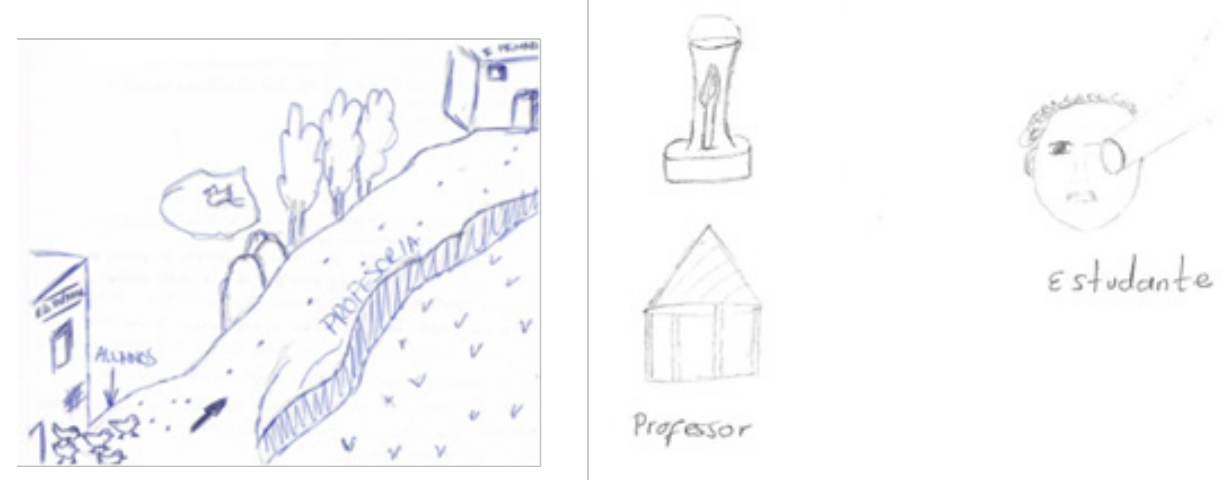

Fuente: Elaboración de los alumnos.

d) Metáforas autorreferenciadas

Estas son metáforas de difícil clasificación en las tres categorías anteriores. En el grupo de Brasil no hemos encontrado metáforas para el profesor en esta categoría. En el grupo de España hemos clasificado en esta categoría para el profesor la de la nadadora, que comienza su curso de natación con ganas, fuerzas e ilusión (emoción positiva social) para que los alumnos aprendan, o la del cantero (Figura 8) que utiliza el cincel y el mazo para enseñar a labrar a los aprendices-alumnos para que se vuelvan expertos. En otros estudios (CRAWFORD, 2000) hemos encontrado la metáfora conductista-transmisiva para el profesor que trabaja la materia prima-alumno y la moldea a su gusto (joyero, alfarero, cantero, etc.), pero en este caso profesor y alumno trabajan la materia prima. Otro participante se identifica con un edificio con buenos cimientos sobre los que apoyar nuestros conocimientos, resistente a las situaciones problemáticas de la clase y de diseño moderno para adaptar la metodología a los tiempos actuales (Figura 8).

En el $2^{\circ}$ dibujo de la Figura 8, la metáfora de los alumnos es la de hormigas, trabajadoras y organizadas, también señalada para los alumnos por un participante de Brasil. Muchas de las metáforas que están encuadradas en la categoría auto-referenciadas representan a animales. Estas metáforas permiten comunicar en pocas palabras contenidos de gran complejidad, asociados en muchos casos a cuentos y leyendas populares. Para los alumnos, otras metáforas identificadas en esta categoría en ambos grupos son las tortugas que aprenden lento pero seguro y tienen que ser trabajadoras y organizadas (MARTÍNEZ; SAULEDA; HUBER, 2001; SABAN, 2010), asociadas a las emociones positivas sociales de la euforia, satisfacción y el ánimo, y a la emoción neutra de la sorpresa. En el grupo de España se han identificado las abejas que están en alerta todo el tiempo intentando revolotear. En la Figura 9 se representan algunos dibujos de animales del grupo de Brasil: osos, gatos, cachorros, pájaros. 
Figura 8. Metáforas del profesor cantero y la de los alumnos-aprendices y del profesor edificio con buenos cimientos (grupo de España)
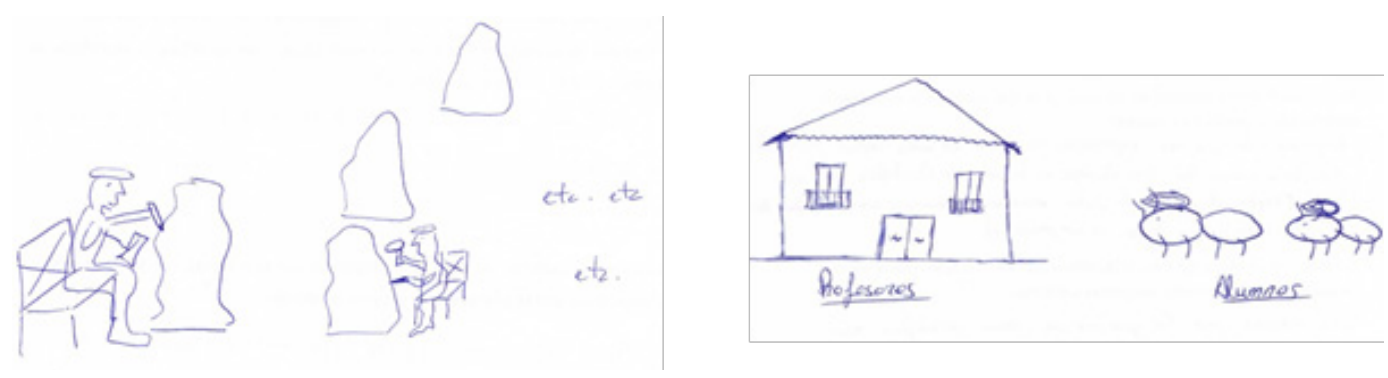

Fuente: Elaboración de los alumnos.

Figura 9. Dibujos de animales del grupo de Brasil para representar a los estudiantes

Fuente: Elaboración de los alumnos.

Finalizamos con el dibujo de la Figura 10 de un participante del grupo de España, que representa al profesor como un camaleón, ya incluido anteriormente entre las cognitivas, pero que incluye una gran cantidad de animales. Para este profesor, el camaleón según el contexto y las características de cada alumno-tortuga, se acercará a ellos lentamente nadando como un pato, rápidamente como una liebre, o volando y sorteando obstáculos como un pájaro. Además, en cada camino hay obstáculos en el aprendizaje representados por un lince, un cocodrilo y un león. El participante asocia a estas metáforas la emoción positiva básica de la felicidad y las emociones positivas sociales del entusiasmo y la confianza. 
Figura 10. El profesor como un camaleón, que puede transformarse en pato, liebre o paloma y seguir diferentes itinerarios, cada uno con sus obstáculos: lince, cocodrilo o león (Grupo de España)

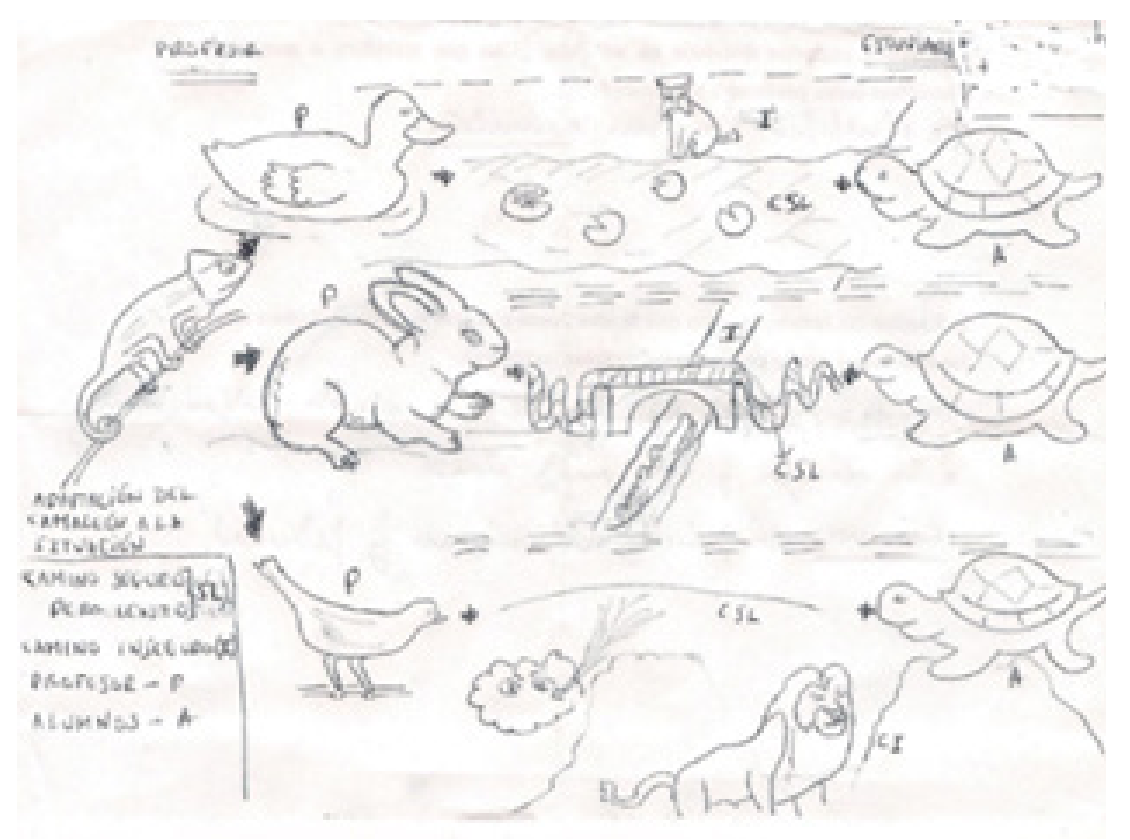

Fuente: Elaboración de los alumnos.

\section{Conclusiones e implicaciones}

La mayoría de los participantes han sido capaces de conceptualizar su roles en forma de metáforas. Algunos de ellos han expresado metáforas correspondientes a más de una categoría, en algunos casos con significados distintos.

Tanto en el grupo de España como en el de Brasil, la mayoría de las metáforas para el rol del profesor se encuadran en la categoría cognitiva/constructivista, seguida de la conductista/transmisiva, y en mucho menor número las catalogadas como situadas y autorreferenciadas, categoría esta última sin metáforas en el grupo de Brasil. Para el aprendizaje del alumnado, en ambos grupos de Brasil y España también son mayorías la metáforas encuadradas en la categoría cognitiva/constructivista. En el grupo de España les siguen las conductistas/transmisivas y las autorreferenciadas, invirtiéndose el orden en el grupo de Brasil. En ambos grupos el menor número de metáforas para los estudiantes se encuentra en la categoría situadas/social.

Un resultado significativo, es que en el grupo de España las metáforas no están asociadas a contenidos concretos, sino que son expresión de una visión general de la enseñanza y del rol del profesor. En cambio, en el grupo de Brasil se han representado metáforas relacionadas con el contenido formativo de profesores de biología y de química 
La mayoría de las emociones expresadas para el profesor son positivas: la emoción primaria/básica de felicidad/alegría, y emociones positivas sociales como entusiasmo, confianza, paciencia, valor, orgullo o curiosidad. También, se expresa la emoción neutra de la sorpresa, pero de gran potencialidad para el aprendizaje de contenidos científicos. En mucha menor medida se expresan las emociones primarias negativas del temor y la tristeza, y la emoción negativa social de la frustración.

Con respecto a las implicaciones, las metáforas se pueden convertir en una herramienta potente para que los futuros profesores reflexionen sobre sus concepciones, actitudes, emociones y roles profesionales (MELLADO, L. et al., 2014; PAAVOLA; HAKKARAINEN, 2005). Los futuros profesores tienen que ser conscientes de sus propias metáforas, de su relación con sus concepciones, actitudes y sentimientos y de su práctica en el aula, para que a través de procesos metacognitivos y metaemocionales, puedan controlar y autorregular los cambios en sus propias metáforas (SEUNG; PARK; NARAYAN, 2011). En particular la reflexión sobre los dibujos realizados por los profesores también se reconoce como una herramienta para conocer las propias concepciones y para iniciar cambios en la práctica del aula (MARKIC; EILKS, 2015). Hijazo-Gascón (2011) habla de inteligencia metafórica y considera que su adquisición podría ser muy útil para desarrollar distintas estrategias en los procesos de enseñanza/aprendizaje.

Sin embargo, Mahlios, Massengill-Shaw e Barry (2010) señalan la dificultad que tienen los profesores para cambiar sus metáforas, que están en gran parte determinadas por sus largos años de escolaridad como alumnos. Tobin y Fraser (1989) abogan no solo por la reflexión sobre las propias metáforas, sino también por introducir durante la formación inicial una variedad de metáforas, lo cual permitiría a estos profesores comprender su potencial, reflexionar sobre sus propias metáforas y elaborar nuevas metáforas consistentes con los modelos de enseñanza que quieren implementar. Todo ello implica la puesta en marcha durante la formación del profesorado, de programas de intervención metacognitivos y metaemocionales, que tengan en cuenta estos resultados y su implicación en la identidad profesional de los docentes y en los procesos de enseñanza y aprendizaje, algo con lo que nuestro grupo de investigación está actualmente comprometido.

\section{Agradecimientos}

Este trabajo ha sido financiado por el proyecto de investigación EDU2012-34140 del Ministerio de Economía y Competitividad de España, la Junta de Extremadura y los Fondos Europeos de Desarrollo Regional.

\section{Referencias}

ALARCÓN, P. et al. Metáforas para profesor y estudiante de pedagogía, en un grupo de estudiantes de pedagogía chilenos. Revista Actualidades Investigativas en Educación, San José, v. 14, n. 2, p. 1-31, 2014. Disponible en: <http://dx.doi.org/10.15517/aie. v14i2.14829>. Visitado el: 30 nov. 2016. 
Las metáforas sobre el profesor y el aprendizaje ...

BELLOCCHI, A. et al. Emotional climate and high quality learning experiences in science teacher education. Journal of Research in Science Teaching, Hoboken, v. 51, n. 10, p. 1301-1325, 2014.

BEN-PERETZ, M.; MENDELSON, N.; KRON, F. W. How teachers in different educational contexts view their roles. Teaching and Teacher Education, Oxford, v. 19, n. 2, p. 277-290, 2003.

BORRACHERO, A. B. et al. Emotions in prospective secondary teachers when teaching science content, distinguishing by gender. Research in Science \& Technological Education, Abingdon, v. 32, n. 2, p. 182-215, 2014.

BOUJAOUDE, S. Conceptions of science teaching revealed by metaphors and answers to open-ended questions. Journal of Science Teacher Education, Dordrecht, v. 11, n. 2, p. 173-186, 2000.

BRÍGIDO, M. et al. Prospective primary teachers' self-efficacy and emotions in science teaching. European Journal of Teacher Education, Abingdon, v. 36, n. 2, p. 200-217, 2013.

BUARAPHAN, K. Metaphorical roots of beliefs about teaching and learning science and their modifications in the standard based science teacher preparation programme. International Journal of Science Education, Abingdon, v. 33, n. 11, p. 1571-1595, 2011.

BULLOUGH JR., R. V. Exploring personal teaching metaphors in preservice teacher education. Journal of Teacher Education, Thousand Oaks, v. 42, n. 1, p. 121-140, 1991.

CONNELLY, F. M.; CLANDININ, D. J.; HE, M. F. Teacher’ personal practical knowledge on the professional knowledge landscape. Teaching and Teacher Education, Oxford, v. 11, n. 7, p. 665-674, 1997.

CONTENÇAS, P.; LEVY, T. A função da metáfora na linguagem da ciência. Revista de Educação, Lisboa, v. 8, n. 2, p. 77-82, 1999.

CRAWFORD, B. A. Embracing the essence of inquiry: new roles for science teacher. Journal of Research in Science Teaching, Hoboken, v. 39, n. 7, p. 916-937, 2000.

DAMASIO, A. Y el cerebro creó al hombre. Barcelona: Editorial Destino, 2010.

DÁVILA, M. A. et al. Evolución de las emociones que experimentan los estudiantes del grado de maestro en educación primaria, en didáctica de la materia y la energía. Revista Eureka sobre Enseñanza y Divulgación de las Ciencias, Cadiz, v. 12, n. 3, p. 550-564, 2015. Disponible en: <http:// rodin.uca.es/xmlui/handle/10498/17609>. Visitado el: 30 nov. 2016.

DAY, C.; LEICH, R. Teachers' and teacher educators' lives: the role of emotion. Teaching and Teacher Education, Oxford, v. 17, n. 4, p. 403-415, 2001.

DE BUSTOS, E. La metáfora: ensayos transdisciplinares. Madrid: Fondo de Cultura Económica, 2000. 
DUFFÉ MONTALVÁN, A. L. Reflexiones psicolingüísticas y didácticas sobre el estudio de metáforas y modismos. Didáctica: lengua y literatura, Madrid, v. 16, p. 3344, 2004. Disponible en: <http://revistas.ucm.es/index.php/DIDA/article/view/ DIDA0404110033A/19328>. Visitado el: 30 nov. 2016.

GRANT, G. E. The sources of structural metaphors in teacher knowledge: three cases. Teaching and Teacher Education, Oxford, v. 8, n. 5-6, p. 433-440, 1992.

GUERRERO, M. C. M.; VILLAMIL, O. S. Metaphorical conceptualizations of ESL teaching and learning. Language Teaching Research, London, v. 6, n. 2, p. 95-120, 2002.

GURNEY, B. F. Tugboats and tennis games: preservice conceptions of teaching and learning revealed through metaphors. Journal of Research in Science Teaching, Hoboken, v. 32, n. 6, p. 569-583, 1995.

HAMILTON, E. Picture this: multimodal representations of prospective teachers' metaphors about teacher and teaching. Teaching and Teacher Education, Oxford, v. 55, p. 33-44, 2016. Disponible en: <http://dx.doi.org/10.1016/j.tate.2015.12.007>. Visitado el: 30 nov. 2016.

HARGREAVES, A. Educational change takes ages: life, career and generational factors in teachers' emotional responses to educational change. Teaching and Teacher Education, Oxford, v. 21, n. 8, p. 967-983, 2005.

HIJAZO-GASCÓN, A. Las metáforas conceptuales como estrategias comunicativas y de aprendizaje: una aplicación didáctica de la lingüística cognitiva. Hispania, Walled Lake, v. 94, n. 1, p. 142-154, 2011.

IZQUIERDO AYMERICH, M. La química ¿emociona? In: MELLADO JUMÉNEZ, V. et al. (Ed.). Las emociones en la enseñanza y el aprendizaje de las ciencias y las matemáticas. [Badajoz]: DEPROFE, 2013. v. 2, p. 307-328.

KIM, T.; DANFOT'TH, S. Non-authoritative approach to supervision of student teachers: cooperating teachers' conceptual metaphors. Journal of Education for Teaching, Abingdon, v. 38, n. 1, p. 67-82, 2012.

KING, D. et al. Emotionally intense science activities. International Journal of Science Education, Abingdon, v. 37, n. 12, p. 1886-1914, 2015.

KINOUCHI, O.; KINOUCHI, J. M.; MANDRA, A. A. Metáforas científicas no discurso jornalístico. Revista Brasileira de Ensino de Física, São Paulo, v. 34, n. 4, p. 1-12, 2012. Disponible en: < http://dx.doi.org/10.1590/S1806-11172012000400020>. Visitado el: 30 nov. 2016.

KORTHAGEN, F. A. J. La práctica, la teoría y la persona en la formación del profesorado. Revista Interuniversitaria de Formación del Profesorado, Zaragoza, v. 24, n. 2, p. 83101, 2010. Disponible en: <http://www.redalyc.org/articulo.oa?id=27419198005>. Visitado el: 30 nov. 2016.

LAKOFF, G.; JOHNSON, M. Metáforas de la vida cotidiana. Madrid: Cátedra, 1986. 
LEAVY, A. M.; McSORLEY, F. A.; BOTÉ, L. A. An examination of what metaphor construction reveals about the evolution of preservice teachers' beliefs about teaching and learning. Teaching and Teacher Education, Oxford, v. 23, n. 7, p. 1217-1233, 2007.

LÖFSTRÖM, E. et al. Images in research on teaching and learning in higher education. In: HUISMAN, J.; TIGHT, M. (Ed.). Theory and method in higher education research. London: Emerald, 2015. v. 1, p. 191-212.

MAHLIOS, M.; MASSENGILL-SHAW, D.; BARRY, A. Making sense of teaching through metaphors: a review across three studies. Teachers and Teaching: theory and practice, Abingdon, v. 16, n. 1, p. 49-71, 2010.

MARKIC, S.; EILKS, I. Evaluating drawing to explore chemistry teachers' pedagogical attitudes. In: MARKIC, S.; ORGILL, M. (Ed.). Affective dimensions in chemistry education. Berlin: Springer, 2015. p. 259-278.

MARTÍNEZ, M. A.; SAULEDA, N.; HUBER, G. H. Metaphors as blueprints of thinking about teaching and learning. Teaching and Teacher Education, Oxford, v. 17, n. 8, p. 965977, 2001.

MCGRATH, I. Using insights from teachers' metaphors. Journal of Education for Teaching, Abingdon, v. 32, n. 3, p. 303-317, 2006.

MELLADO, L.; BERMEJO, M. L.; MELLADO, V. Personal metaphors of prospective secondary economics and science teachers. Asia Pacific Journal of Teacher Education, Melbourne, v. 40, n. 4, p. 395-408, 2012.

MELLADO, L. et al. Las emociones en las metáforas personales de futuros profesores de ciencias, de economía y de psicopedagogía. In: (Ed.). Las emociones en la enseñanza y el aprendizaje de las ciencias y las matemáticas. [Badajoz]: DEPROFE, 2013a. v. 2, p. 415-436.

. Evolución de los modelos docentes de futuros profesores de economía de secundaria, a través de la metáfora. Didáctica de las Ciencias Experimentales y Sociales, Valencia, n. 30, p. 23-44, 2016. Disponible en: <https://ojs.uv.es/index.php/dces/article/ view/7230/8458>. Visitado el: 29 nov. 2016.

. Las metáforas emocionales de los estudiantes de educación primaria y educación infantil. International Journal of Developmental and Educational Psychology, Badajoz, v. 25, n. 1, p. 281-289, 2013b. Disponible en: <http://dehesa.unex.es/handle/10662/618>. Visitado el: 29 nov. 2016.

. Las metáforas personales de estudiantes de psicopedagogía sobre el profesor y el aprendizaje. Campo Abierto, Badajoz, v. 33, n. 1, p. 153-170, 2014. Disponible en: < http:// mascvuex.unex.es/revistas/index.php/campoabierto/article/view/1559/995>. Visitado el: 29 nov. 2016.

MELLADO, V. et al. Las emociones en la enseñanza de las ciencias. Enseñanza de las Ciencias, Barcelona, v. 32, n. 3, p. 263-288, 2014. Disponible en: <http://dx.doi. org/10.5565/rev/ensciencias.1478>. Visitado el: 29 nov. 2016. 
OLTHOUSE, J. How do preservice teachers conceptualize giftedness?: a metaphor analysis. Roeper Review, Philadelphia, v. 36, n. 2, p. 122-132, 2014.

OTERO, M. R. Emociones, sentimientos y razonamientos en didáctica de las ciencias. Revista Electrónica de Investigación en Educación en Ciencias, Buenos Aires, v. 1, n. 1, p. 24-53, 2006. Disponible en: < http://ppct.caicyt.gov.ar/index.php/reiec/article/ view/7350/6603>. Visitado el: 29 nov. 2016.

PAAVOLA, S.; HAKKARAINEN, K. The knowledge creation metaphor: an emergent epistemological approach to learning. Science $\boldsymbol{\&}$ Education, Dordrecht, v. 14, n. 6, p. 535$557,2005$.

PATCHEN, T.; CRAWFORD, T. From gardeners to tour guides: the epistemological struggle revealed in teacher-generated metaphors of teaching. Journal of Teacher Education, Thousand Oaks, v. 62, p. 286-298, 2011.

PINNEGAR, S. et al. Exploring preservice teachers' metaphor plotlines. Teaching and Teacher Education, Oxford, v. 27, n. 3, p. 639-647, 2011.

REBOLLO, M. A. et al. Metáforas que usan las profesoras en los procesos de cambio educativo con perspectiva de género. Profesorado: revista de curriculum y formación de profesorado, Granada, v. 17, n. 1, p. 43-56, 2013. Disponible en: < http://www.redalyc.org/ articulo.oa?id $=56726350004>$. Visitado el: 29 nov. 2016.

RITCHIE, S. M. The craft of intervention: a personal practical theory for a teacher's withingroup interactions. Science Education, Hoboken, v. 83, n. 2, p. 213-231, 1999.

. Metaphor as a tool for constructivist science teaching. International Journal of

Science Education, Abingdon, v. 16, n. 3, p. 293-303, 1994.

RITCHIE, S. M.; AUBUSSON, P. J.; HARRISON, A. G. Metaphorically thinking. In: AUBUSSON, P. J.; HARRISON, A. G.; RITCHIE, S.T. (Ed.). Metaphor and analogy in science education. Dordrecht: Springer, 2006. p. 189-195.

SABAN, A. Prospective teachers' metaphorical conceptualizations of learner. Teaching and Teacher Education, Oxford, v. 26, n. 2, p. 290-305, 2010.

SEFEROGLU, G.; KORKMAZGIL, S.; ÖLÇÜ, Z. Gaining insights into teachers’ ways of thinking via metaphors. Educational Studies, Abingdon, v. 35, n. 3, p. 323-335, 2009.

SEUNG, E.; PARK, S.; NARAYAN, R. Exploring elementary pre-service teachers' beliefs about science teaching and learning as revealed in their metaphor writing. Journal of Science Education and Technology, Dordrecht, v. 20, n. 6, p. 703-714, 2011.

SHAW, D. M.; BARRY, A.; MAHLIOS, M. Preservice teachers' metaphors of teaching in relation to literacy beliefs. Teachers and Teaching: theory and practice, Abingdon, v. 14, n. 1, p. 35-50, 2008.

SILLMAN, K.; DANA, T. M. Metaphor: a tool for promoting prospective elementary teachers' participation in science teacher learning community. Journal of Science Teacher Education, Dordrecht, v. 12, n. 2, p. 87-106, 2001. 
THOMAS, L.; BEAUCHAMP, C. Understanding new teachers' professional identities through metaphor. Teaching and Teacher Education, Oxford, v. 27, n. 4, p. 762-769, 2011.

TOBIN, K.; FRASER, B. J. Barriers to higher-level cognitive learning high school science.

Science Education, Hoboken, v. 73, n. 6, p. 659-582, 1989.

TOBIN, K.; TIPPINS, D. J. Metaphors as seeds for conceptual change and the improvement of science education. Science Education, Hoboken, v. 80, n. 6, p. 711-730, 1996.

TOBIN, K.; TIPPINS, D. J.; GALLARD, A. J. Research on instructional strategies for teaching science. In: GABEL, D. (Ed.). Handbook of research on science teaching and learning. New York: MacMillan, 1994. p. 3-44.

VELASCO SACRISTÁN, M. S. Publicidad y género: propuesta, diseño y aplicación de un modelo de análisis de las metáforas de género en la publicidad impresa en lengua inglesa. 2002. 735 h. Tesis (Doctoral) - Facultad de Filosofía y Letras, Universidad de Valladolid, Alicante, 2002.

WEBER, S.; MITCHELL, C. Drawing ourselves into teaching: studying the images that shape and distort teacher education. Teaching and Teacher Education, Oxford, v. 12, n. 3, p. 302-313, 1996.

ZEMBYLAS, M. Emotion metaphors and emotional labor in science teaching. Science

Education, Hoboken, v. 88, n. 3, p. 301-324, 2004. 